\title{
Separation of immature granules containing color dye from the rat parotid gland
}

\author{
Osamu Katsumata-Kato, Junko Fujita-Yoshigaki, Takanori Narita, and \\ Hiroshi Sugiya \\ Department of Physiology, Nihon University School of Dentistry at Matsudo, Matsudo, Japan
}

\begin{abstract}
Parotid acinar cell contains many secretory granules. Most of granules are mature, but only little immature granules are included. These immature granules are not enough for investigation of granule maturation. In this study, we show an easy method of separation of immature granules from the rat parotid gland. In addition, we succeeded in detection of color dye in the granules. These results suggest that secretory granules can be visualized through endocytosis. J. Med. Invest. 56 Suppl. : 391-392, December, 2009
\end{abstract}

Keywords : parotid gland, secretory granules, endocytosis

\section{INTRODUCTION}

It has been reported that secretory granules were isolated according to their degree of maturation (1). They were examined using pulse-chase labeling analysis. Distribution of labeled granules was shifted to high-density in Percoll density gradient on time dependently This means that immature granules are separated mature granules into low-density fractions by Percoll density centrifugation We have examined that characterization of membrane protein in immature compared with mature granules (2). Syntaxin 6 and VAMP4 were concentrated on membrane of immature granules, whereas VAMP2 was concentrated in mature granules. Moreover, diameter of immature granule was smaller than that of mature one. These have been reported characterization of immature granules. For investigation of granule maturation, we need much more immature granules. Therefore, we conceived an easy method

Received for publication October 7, 2009 ; accepted October 14, 2009.

Address correspondence and reprint requests to Osamu Katsumata-Kato, Department of Physiology, Nihon University School of Dentistry at Matsudo, 2-870-1 Sakaecho-Nishi, Matsudo, Chiba 271-8587, Japan and Fax : +81-47-360-9327. for isolation of immature granules from the rat parotid gland.

\section{METHODS}

$\beta$-agonist isoproterenol (IPR, $5.5 \mathrm{mg} / \mathrm{kg}$ ) was injected into the abdominal cavity for a male SpragueDawley rat. Dispersed acinar cells were isolated from the parotid glands by incubation with KrebsRinger-bicarbonate solution containing collagenase $(1.4 \mathrm{mg} / \mathrm{ml})$ and hyaluronidase $(0.2 \mathrm{mg} / \mathrm{ml})$ at $37^{\circ} \mathrm{C}$ for 1 hour. For electron microscopy, the parotid gland was fixed perfusion with Karnovsky's fixative solution (2\% paraformaldehyde and $2.5 \%$ glutaraldehyde). After embedding, the parotid gland was observed by transmission electron microscopy (JEOL, JEM-1010). Secretory granules were isolated into low-density fraction after Percoll density centrifugation, and then washed with buffer (300 mM sucrose, $5 \mathrm{mM}$ MOPS pH 6.8, 1 mM Benzamidine, $0.4 \mathrm{mM}$ PMSF). Diameter of new-formed granules was measured using electron micrograph. Granules membranes were recovered by ultra-centrifugation at $100,000 \mathrm{x} \mathrm{g}$ for $30 \mathrm{~min}$ in hypotonic buffer. 


\section{RESULTS AND DISCUSSION}

We observed secretory granules in the parotid gland by electron microscopy. Acinar cell had a lot of secretory granules in the resting condition. At 2 hours after injection with IPR, secretory granules completely disappeared from acinar cells by exocytosis, and microvilli were observed in lumen, Newformed granules were observed near lumen after 5 hours after injection. The new-formed granules were separated from the glands of rats treated with IPR for 5 hours by Percoll density gradient, and were collected into low-density fractions. Diameter of the new-formed granule was around $500 \mathrm{~nm}$, which was half the size of mature granule. Regarding membrane components in the new-formed granules, syntaxin6 and VAMP4, SNARE proteins in immature granules, were concentrated into the newformed granule membrane (3). These characterizations of the new-formed granules were consistent with immature granules as previously reported (2).

Next we examined a possibility of granule formation by endocytosis, because the immature granules were observed near lumen in parotid gland by electron microscopy. After 2 hours treatment by IPR injection for depletion of secretory granules, parotid glands were removed from the rat, and were incubated with Lucifer Yellow (LY), a cell impermeable dye, for 5 hours under $\mathrm{O}_{2} / \mathrm{CO}_{2}(95 / 5 \%)$ gas-phase. After the incubation, immature granules were observed in the parotid gland by electron microscopy. Interestingly, LY was detected in the immature granules by confocal laser microscopy. In the immature granules purified from the parotid glands, LY was also detected by micro-plate reader (Ex/Em 485/ 535).

\section{CONCLUSION}

We established an easy method for separation of new-formed granules from the rat parotid gland. The characterization of new-formed granules was same as that of immature granules. Because color dye was detected in purified new-formed granules, endocytosis contributes to the granule formation. These results suggest that secretory granules can be visualized.

\section{REFERENCES}

1. Zastrow M, Castle JD : Protein sorting among two distinct export pathways occurs from the content of maturing exocrine storage granules. J Cell Biol 105 : 2675-2684, 1987

2. Fujita-Yoshigaki J, Katsumata O, Matsuki M, Yoshigaki T, Furuyama S, Sugiya H : Difference in distribution of membrane proteins between low- and high-density secretory granules in parotid acinar cells. Biochem Biophys Res Comm 344 : 283-292, 2006

3. Katsumata O, Fujita-Yoshigaki J, HaraYokoyama M, Yanagishita M, Furuyama S, Sugiya H : Syntaxin6 separates from GM1arich membrane microdomain during granule maturation. Biochem Biophys Res Comm 357 : 1071-1077, 2007 